\title{
The demographic transition in the Democratic Republic of Congo: facts and challenges to reach a demographic dividend.
}

\author{
Laura Franco-Henao', Carmen Rodriguez-Sumaza ${ }^{2}$, Carlos Borondo-Arribas ${ }^{2}$ \\ \& Emmanuel Muzigirwa-Muke ${ }^{3}$ \\ ${ }^{1}$ MA Development Studies, University of Sussex, United Kingdom \\ ${ }^{2}$ University of Valladolid, Spain \\ ${ }^{3}$ Catholic University of Bukavu, Democratic Republic of Congo
}

Email: sumaza@eco.uva.es

\begin{abstract}
Background: The channels linking the demographic and economic situation of a population are numerous. We focus on the process of a demographic transition and the demographic dividend that Sub-Saharan Africa and, in particular, the Democratic Republic of Congo (DRC), are currently undergoing.

Data source and methods: Secondary data are used to highlight the diverse paths of demographic transition in Sub-Saharan African countries. Additionally, the specific situation of the DRC is selected as a case study.

Results: The potential of Sub-Saharan Africa to enjoy a demographic dividend is exceptional. Although the DRC is in the group of the least advanced countries, its increasing share of working age population is a key to reap the benefits of the potential economic growth.

Conclusion: There are some recent economic and social advancements in the DRC, but the benefits of its demographic performance are dependent on whether government and institutions are capable of responding to current circumstances with targeted, effective and coordinated policies.
\end{abstract}

Keywords: demographic transition, demographic dividend, economic growth, public policies, the Democratic Republic of Congo.

\section{Introduction}

Sub-Saharan Africa is currently facing a demographic transition (DT) which involves rapid population growth and, in particular, an increase in the share of the working age population (SWAP) in its first phase. The central object of this paper is to evaluate the possibility of these changes to generate a demographic dividend (DD) or, in other words, to encourage economic growth. We will focus on a particular context, the Democratic Republic of Congo (DRC).

The starting point is the DT, defined as a prolonged process of reducing mortality and fertility rates, which has already taken place in some continents such as Europe or North America and is very advanced in Latin America and Asia. These changes are more recent in the case of Africa. The DT has offered countries the chance to develop and increase their welfare. As the decrease in mortality is prior and more intense than the decline in fertility, the DT usually generates in its early stages a sustained increase in the proportion of the working age population. This increase can generate in turn a positive effect on Gross Domestic Product (GDP) for several decades through the increase of the labour rate (ratio of employment on total population) (although not guaranteed). This potential effect is called the demographic dividend (DD). The DD illustrates the interplay between variations in the age structure of a population due to the DT and rapid economic growth. It describes the potential economic growth that can take place in a country during several decades in response to those circumstances.

The main goal of this work is to explore the potential effects of the DT on economic growth in the DRC and to determine which policies should be conducted to encourage the emergence of a DD. The DRC is part of the group of African countries currently beginning to move from high to low mortality and fertility rates. To gain a further understanding of the DT situation in this country, we look at other regions that have recently experienced the same demographic circumstances, such as Latin America and East Asia. Furthermore, examining previous cases is necessary to consider possible policies that could be conducted to make the DD feasible and reap the benefits. Yet, we are aware that Sub-Saharan Africa faces a different context. 
Indeed, we address more specifically the following three main objectives: (i) to explore the stages of the DT for African, Asian and the Latin American regions; (ii) to analyze the DT for the DRC and its potential to benefit from the resultant DD; and (iii) to discuss and recommend policies the DRC can adopt to harness the DT from opportunities presented by the DT. The initial comparative analysis of the DT in different regions is aimed to illustrate the international context of the DRC, our particular case study.

The paper is divided as follows. The second section addresses the issue of the theoretical framework, remarking the key points found during the literature research about the relationships among macroeconomics, demographic dividends and demographic transitions. In addition, possible policies to foster the DD are analysed in this section. The third section provides an overview of the data and methods used to compute the DD. The fourth section describes the results. We begin with the DT in Sub-Saharan Africa, with an original and comparative empirical work to visualize the effects of the DT in the five standard (UN defined) sub-groups of countries within the area: Northern, Southern, Eastern, Western and Middle Africa. Then, we focus on the specific situation of DRC, analyzing the main demographic indicators, the evolution of its population structure and the possibilities of a DD. Based on the progress made towards the achievement of the Millennium Development Goals, we discuss in section 5 some of the central areas where changes are needed and an intervention could generate more benefits. Finally, we end the paper with the conclusions, containing some proposals that could assist DRC in achieving the goal of maximizing the DD.

Literature review: factors and policies for the demographic dividend.

Two main demographic trends are currently taking place in the world. First, the process of ageing in the developed world, especially in Europe, North America and Japan. It is considered the biggest challenge the world is facing (Bloom, 2016). Second, the fast population growth with an increase in the SWAP in developing countries. We will focus on the latter for the purpose of this paper.

\section{The $D T$ as the starting point}

The DD can boost economic growth in a country for several decades because of certain changes in the structure of its population. The DT is generally conceived as the evolution from a rural society with high fertility and mortality rates to an industrial and urban society in which both rates are low (Lee \& Mason, 2006). The reduction of mortality usually occurs before and with higher intensity than that of fertility; therefore, the DT causes in its first phases an increase in population growth. The Infant Mortality Rate (IMR) also decreases, leading to a greater infant population. However, as infant survival improves, families become more comfortable with smaller size families and fertility starts to decline. The transition to low fertility means that the young dependent population falls in relation to the working-age population over time (Bloom, Kuhn, \& Prettner, 2016). If the labour force (and the SWAP) increases faster than the dependent population, it will release resources that can be invested in economic development and family welfare. If everything else remains constant, income per capita might increase faster. This is called the first dividend (Lee \& Mason, 2006).

Some consequences of this process need to be highlighted. First, reductions in fertility allow for greater female labour force participation. More female participation in the labour market helps to raise the ratio of workers to the dependent population. Second, the reduction of the family size allows families and governments to invest more in their children's health care and education (rising human capital); the so-called quantitative-quality trade-off (Mason, Lee \& Jiang, 2016). Moreover, due to higher life expectancy, the benefits of investing in human capital is larger. Higher human capital can boost aggregate productivity growth once the young cohorts enter the workforce (Bloom et al., 2016). Finally, the falling dependency rate releases economic resources that were previously used to take care of the dependent population and now can be saved and invested in productive capital.

The first DD can last several decades. However, the reduction of fertility rates eventually decreases the growth of the working age population. The low mortality rates along with the improvement of life expectancy increase the number of old people and a population ageing process starts taking place. When the Total Fertility Rate (TFR) stops decreasing and the smaller cohorts begin to retire, the dependency ratio will rise again due to the increase of old-age dependency (Bloom et al., 20I6).

According to Lee and Mason (2006), a second dividend is possible, characterized by a population with a higher working age and longer retirements. They are more likely to accumulate more assets and the savings rate for retirement rises. The investment of these assets increases national income.

To sum up, the first DD is a transitory profit whereas the second DD can result in sustainable development. Regions such as Sub-Saharan Africa have a large potential to experience a DD, depending on the policies their leaders implement (Bloom et al., 2016). This window of opportunity for economic 
growth has been studied for a long time. Drummond et al. (20/4) and Mason (2005) find that crosscountry regression models propose a positive impact of fertility and age structure on economic growth. However, they do not often determine the pathways through which fertility influences the economy.

To gain further understanding, some authors have constructed macrosimulation models of economic growth and parameterized the model's channels from microeconomic studies. The study carried out by Ashraf, Weil \& Wilde (20/3) identifies several channels by which fertility affects the economy. Their results indicate that, for a horizon of fifty years, the four dominant effects are dependency, capital shallowing, schooling and the congestion of fixed factors and, for a horizon of ninety years, capital shallowing followed by the congestion of fixed factors.

The approach taken by Karra, Canning \& Wilde (2015) is based on the work of Ashraf, Weil \& Wilde (2013). Nonetheless, they added three extra mechanisms by which the decline of fertility may produce economic effects. First, they included a connection between the fertility fall and advances in children's health outcomes. Fewer children mean that more investment in their health is feasible which, in turn, promotes their development. This process can lead to rises in human capital and productivity. Second, they include a mechanism through which the variations in population age structure (due to fertility decline) may boost savings rates. Savings rates vary with age at the household level and they are higher during the working phase; therefore, the national level of savings will depend on the age structure of the population. Third, they affirm fertility responds endogenously to variations in the economic conditions; thus, they consider the possibility of further subsequent fertility declines. That is to say that if the fall of fertility raises investment in children's education, this situation is likely to reduce fertility in the next cohort. However, this feedback is slow (only attained when the generation with higher education reaches the childbearing age). In addition, they use a model with three sectors: the modern (with labour, physical and human capital as inputs), the traditional (with labour and land as inputs) and the raw material sector (no inputs). Wages differ across sectors.

Including these mechanisms, they come to the conclusion that reducing the fertility rate by one child per woman can almost double income per capita. This is twice as big as the results obtained by Ashraf et al. (20I3). Karra et al. (20I5)'s model points out that in the short to medium term, the central reason for greater income effects is that the workforce is transferred to the modern sector when fertility is low. In the long run, lower fertility raises female education, which decreases next generation's fertility. Moreover, their study also looks at family planning programs underlining their strong role in reducing the fertility gap between developed and developing regions.

The work of Mason et al (2016) has a similar conceptual approach. Nevertheless, these authors give much greater importance to the influence of the human capital channel and the quantity-quality tradeoff that takes place over the DT. The quantity-quality trade-off consists of greater expenditures on quality per child (human capital enhancing expenditures such as education and health) when the quantity of children falls (income per capita rises). The model proposed by Galor \& Weil (2000) also emphasizes the shift from quantity to quality, but they claim instead that they do so not in response to the level of income but rather in response to technological progress.

Mason et al. (20/6) identify low per child investment in human capital as one of the reasons why low-income countries are poor. Furthermore, the constraints that families face are much greater if the number of children per woman is high. Although development depends on many factors, the DT and the quantity-quality trade-off play a prominent role in this model because they have important and lasting effects on standards of living. Finally, they remarked that the decline in fertility is not necessarily the cause of greater human capital investment. They are mutually reinforcing and influenced by many factors including policies.

\section{Maximising factors of the demographic dividend}

To translate the potential from the DT to a DD requires appropriate policies. With inadequate policies, the rise in SWAP may lead to high rates of unemployment and economic risks. As Drummond et al., (2014) pointed out, the experiences of Asia and Latin America were divergent. Asia's better outcomes are related to greater focus on human and physical capital, higher labour participation rates, and an initial emphasis on labour-intensive export-led growth that created employment opportunities and supported the transition into sectors with higher total factor productivity. On the contrary, a weaker policy atmosphere and the failure to attract enough investment are two of the fundamental reasons of Latin America's less beneficial DD.

The potential effects on income per capita due to the changes that the DT causes are not automatic. Some policies need to be applied to maximize the DD. First, promoting gender equality and the decline of fertility. When fertility does not decrease, it becomes an obstacle for the potential economic growth (the dependency rate does not decrease). In order to achieve this, countries need to overcome 
the social norms underlying persistently high fertility (Bloom et al., 2016). Information and good access to modern contraceptives should be provided as well as a good sexual education. In addition, policies to ease the access to family planning programs increase women's opportunities to enter and/or to stay in the labour market.

The study carried out by Bloom and others' (2009) highlights that eliminating the legal restrictions on abortion promotes fertility reductions significantly. Women must be able to freely decide when and how many children they want to have. Besides the promotion of a greater participation of women in the labour market, the decline in fertility also increases their incomes, contributing to the DD and to develop human capital. Pregnant women's health has to improve in order to reduce the number of mothers that die during birth. Gender equality has to be pursued across all fields.

A second policy consists in facilitating universal access to primary and secondary education. Training policies are also necessary to help people through the transition from the educational to the working phase (UNFPA, 20I4). If the resources invested in youth to raise their chances to have better living conditions are not enough, the process of reducing poverty will be slower.

Third, it is crucial to invest in healthcare and social infrastructures such as schools and hospitals due to the aforementioned reasons. In turn, these investments require the establishment of solid political, financial and economic institutions (Bloom et al., 2016).

Fourth, it is important to promote a stable macroeconomic environment, which contributes to employment creation and increases the paths to obtain incomes for current and future generations. Employment in Sub-Saharan Africa needs to be created at an unprecedented rate (Thakoor \& Wakeman-Linn, 2016). Furthermore, it is necessary to promote socio-political stability, security, good governance and enabling business environment. Security is a difficult goal to achieve in countries recently (or still) affected by wars, conflicts and violence.

Fifth, it is essential to improve the productivity of small companies in rural areas, because more people depend on them. The percentage of population living in rural areas in developing countries is very high; thus, opportunities must be fostered for agriculture, small companies and employment in the formal sector (UNFPA, 20I4).

Sixth, access to financial services has to be guaranteed so savings can be efficiently channelled towards investment and create employment and growth (Thakoor \& Wakeman-Linn, 2016). Access to finance is limited for poor people due to long distances among other reasons. However, new technologies play a prominent role in facilitating access to banks and credit, which in turn, encourages saving. Furthermore, if young people got training in finances and developed their entrepreneurial spirit, it would facilitate the set-up of businesses and start-ups creating employment and growth.

Finally, some countries have some specific advantages (natural resources) or barriers (wars) (UNFPA, 2014) which must be taken into account when designing development policies.

All the policies mentioned above are designed to potentiate the first dividend. However, Lee \& Mason (2006) underline policies towards taking advantage of the second dividend. The most important factor is considered to be the support for the elderly and the incentives towards savings and pension funds accumulations. The process of ageing will cause an increasing burden over families and the government in relation to GDP, so developing countries ought to build solid and reliable financial systems for the population who wish to ensure their financial future.

Data and methods: measuring the demographic dividend

The measure of a country's potential DD is a crucial question in order to address a comparative analysis. GDP per capita can be decomposed by the following formula:

$$
\frac{Y}{N}=\frac{Y}{L} \times \frac{L}{N_{16-64}} \times \frac{N_{16-64}}{N}
$$

where $Y$ is real GDP, $N$ is total population, $L$ represents total workers and $N_{16-64}$ is the working age population. Then, we can measure the rate of growth of GDP per capita by adding the rates of growth of each component of $(\mathrm{I})$.

$$
\widehat{\left(\frac{Y}{N}\right)}=\widehat{\left(\frac{Y}{L}\right)}+\left(\widehat{\frac{L}{N_{16-64}}}\right)+\left(\widehat{\frac{N_{16-64}}{N}}\right)
$$

Therefore, output per capita can increase because of increments in productivity per worker $(\mathrm{Y} / \mathrm{L})$, in the employment rate $\left(L / N_{16-64}\right)$ or in the SWAP $\left(N_{16-}\right.$ $\left.{ }_{64} / \mathrm{N}\right)$, the demographic factor. The DD is measured as the contribution of the SWAP to GDP per capita. We observe that fixing the rest of components (that implies assuming that productivity per worker $(\mathrm{Y} / \mathrm{L})$ and employment rate $\left(L / N_{16-64)}\right.$ remain constant to concentrate on the effects of SWAP alone), an increase in the SWAP causes a direct increment in GDP per capita.

The annual rate of growth of a period is calculated as: 
$g=\left(\frac{X_{t}}{X_{0}}\right)^{\frac{1}{T}}-1$

where $g$ is the annual rate of growth of a variable $X$ in a period of $T$ years, $X t$ is the value of the variable at the end of the period and $X_{0}$ is the value of the variable at the beginning of the period. Using formula (3) we can calculate the rates of growth of each of the components of (2). We use UN (2015) World Population Prospects for population data from 1950 to 2100 , detailed in 5 years age groups. For GDP and employment we use the Penn World Table 9.0 (variables rgdpna and emp).

\section{Results}

\section{The DD in Sub-Saharan Africa}

The DT is experienced differently in each region. In Latin America and East Asia declines in mortality began in the middle of the 1940s, while their fertility rates began falling and their SWAP ascending in the 1960s (Figure I). Africa's SWAP began to increase almost 30 years later. East Asia saw a faster decline in fertility and that explains why the increase in its SWAP was higher than in Latin America. Before Latin America's DT started, its SWAP was similar to Africa.
However, fertility has declined at a much slower rate in Africa; hence, their increase in the SWAP has been slower as well. Asia and Latin America are considered to have achieved their SWAPs' peak and, in a few years, they are predicted to diminish. On the other hand, Africa started its DT around 1985 and its SWAP is expected to keep increasing during this century but reaching lower levels than those previously seen in East Asia and Latin America. Reaping the potential benefits of this situation will depend on the policies they take.

According to UN (20I5), by 2030 the number of people reaching the working age (15-64) in Africa will exceed that of the rest of the continents (even combined). This implies a rapid increase in its SWAP. Sub-Saharan Africa's share over the total working-age population is projected to increase from $8.75 \%$ in 2000 to almost $38 \%$ in 2100 . Thus, almost 4 out of 10 people aged between 15 and 64 (working age population) will be in Sub-Saharan Africa. Incorporating Sub-Saharan Africa's labour force to global supply chains would be favourable for the rest of the world, because of its contribution to lowering the mean age of the global working population.

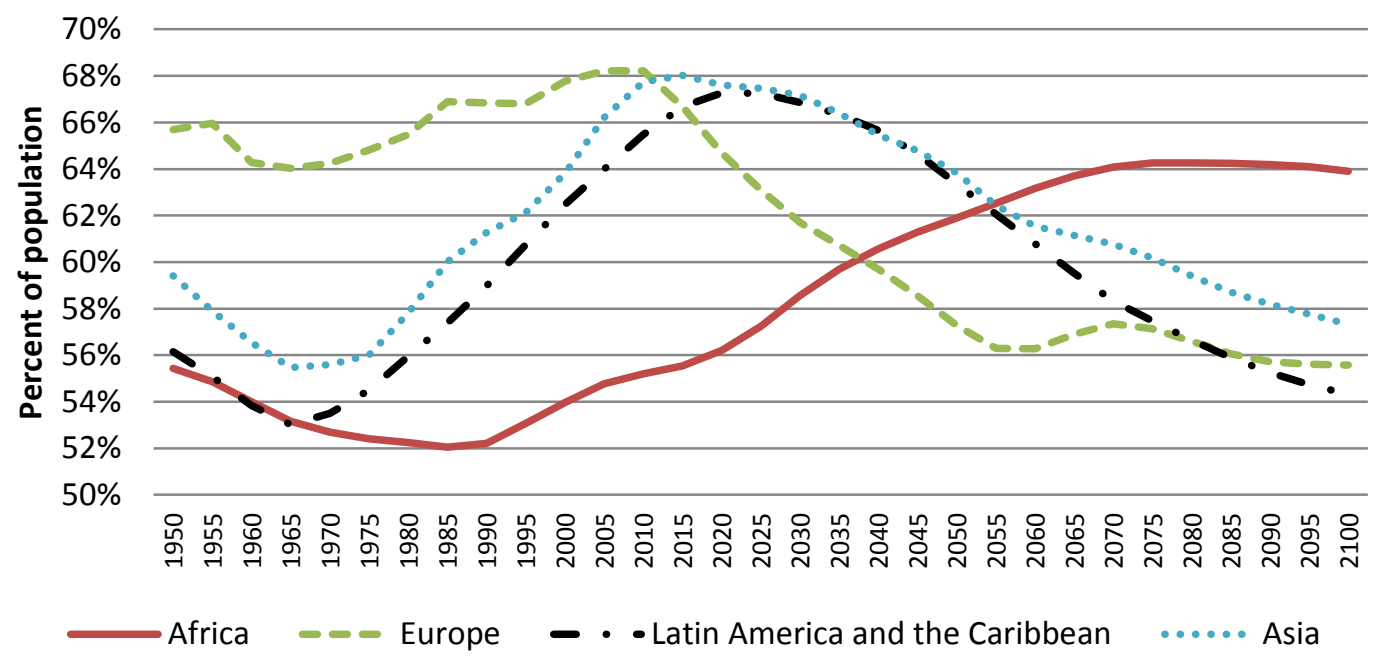

Figure I: Global trends in the SWAP (1950-2100)

Source: Own elaboration with data from UN, World Population Prospects, 2015.

East Asia and Latin America did not implement the same policies and their differences are a useful source of information for African countries through their DTs. Following Wakeman-Linn (2015), East Asia's better performance can be attributed to several factors. First, their policies encouraged a faster DT. East Asian countries launched voluntary population policies that incentivized families to have fewer children and they provided low-cost means (contraceptives such as condoms) to regulate fertility (Canning, Raja, \& Yazbeck, 20I5). As a result, the 4277 fertility decline was accelerated. Second, investments in human capital ensured a more productive workforce. Their governments promulgated education policies which promoted higher productivity through improvements in people's skills and health. Third, employment generation was incentivized by labour market flexibility in wages and a shift to manufacturing sectors which are labour intensive. Governments expanded their manufacturing and service sectors in order to absorb the increased labour supply. Fourth, greater trade http://aps.journals.ac.za 
integration promoted employment, structural transformation and technology transfer. Latin American economies were not as open as those of East Asia. Finally, the increased savings from the DT were channeled toward investment by adopting measures such as tax policies.

On the contrary, as mentioned in section 2, a weak environment policy and their inability to attract enough investment are considered two of the main reasons of Latin America's less beneficial DD (Drummond et al., 20|4).

Africa is the poorest continent in the world. Its demographic situation is a direct consequence of poverty and it affects negatively the possibilities of economic and social development (Canning, Raja, \& Yazbeck, 2015). The whole continent shows some common trends but with outstanding differences in their rates. Regions within Africa vary. North Africa is well into its DT because it saw a rise of its SWAP in the late 60s (Figure 2), roughly at the same time as Latin America and Asia. This increase coincided with a reduction of its TFR (Figure 3). Between 1965 and 2015 its SWAP has increased from $51.80 \%$ to $62.91 \%$ and its TFR has decreased from 6.9 to 3.27 children per woman.
Additionally, whereas in Southern Africa the DT started around the 1960s, in other regions like Middle, West and East Africa the DT is still taking place and the process has been much slower. In Southern Africa, the SWAP has grown from $53.9 \%$ in 1965 to $65.1 \%$ in 2015 and its TFR has declined from 6.1 to 2.5 children per woman (Figure 3 ), getting close to the generational replacement rate (2.I children per woman). As Martín Ruiz (2007) points out, the relatively high fertility rates can be explained by a number of reasons: the average age for first marriage is very low (between 16 and 19 years old); contraception is still scarce, and the increasing process of Islamization in some countries, etc.

In Sub-Saharan Africa as a whole, the DT has started between the end of the 1980s and the beginning of 1990s. Until then, its SWAP had remained low and its TFR high. Sub-Saharan Africa's DT is expected to be slower, as it can be seen in Figures 2 and 3. Its SWAP is predicted to reach Northern Africa's value around 2060. Nevertheless, the speed of the DT and reaping the benefits of a DD will depend on the policies taken during the process.

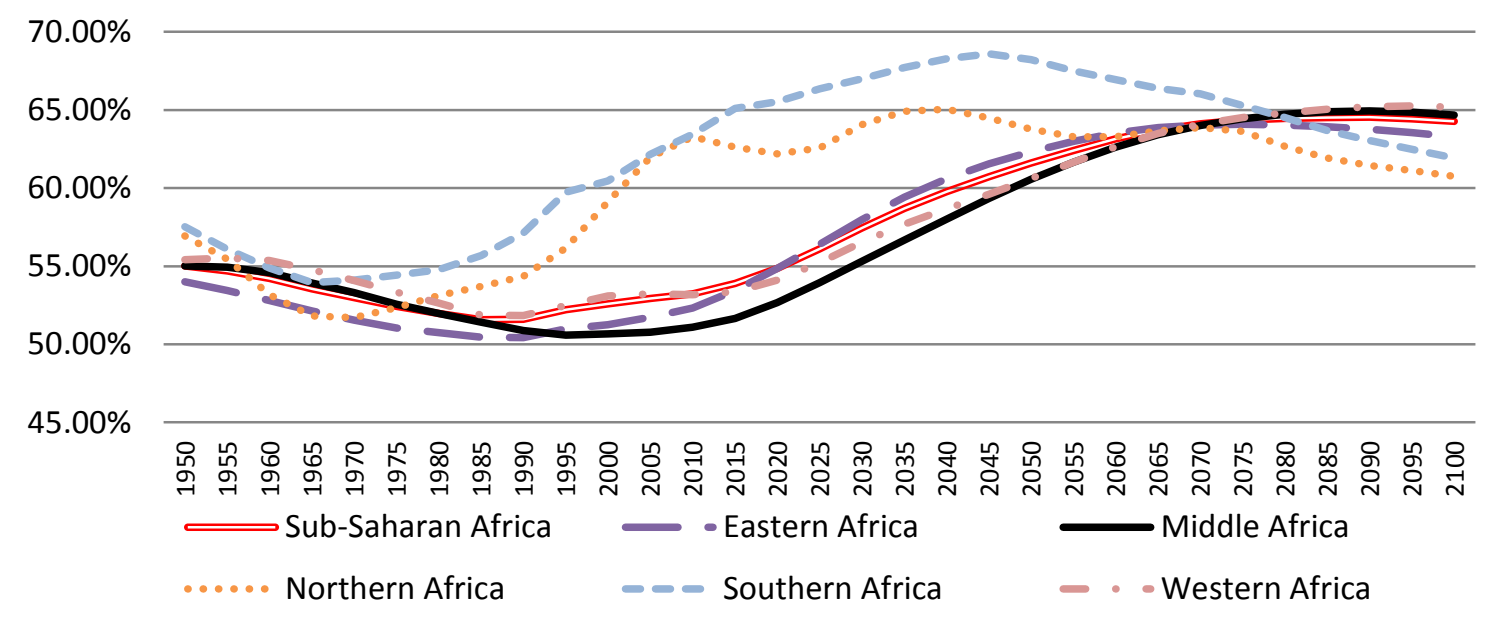

Figure 2: SWAP in different parts of Africa (1950-2100).

Source: Own elaboration with data from UN, World Population Prospects, 2015. 


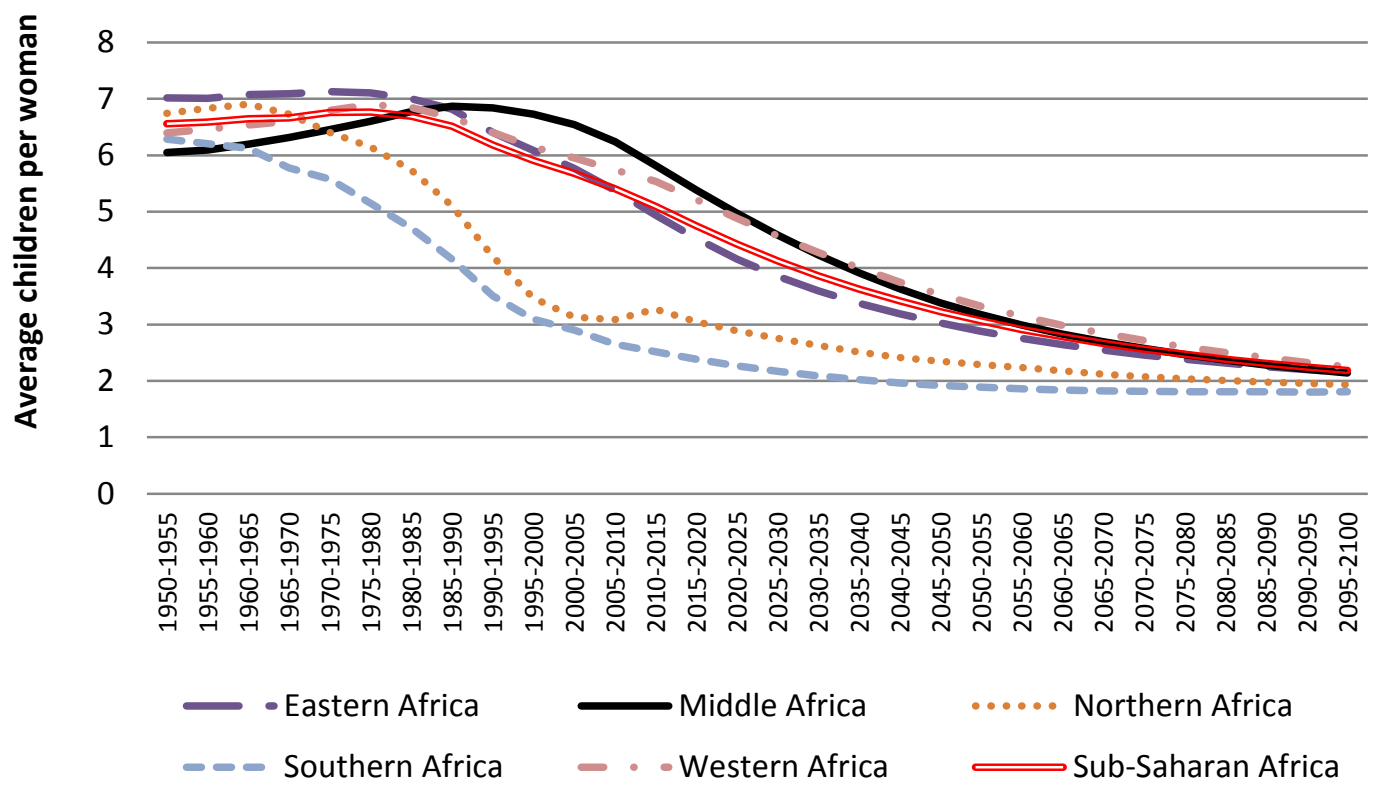

Figure 3: Total Fertility Rates in different parts of Africa (1950-2100)

Source: Own elaboration with data from UN, World Population Prospects, 2015.

These significant differences between Northern and Sub-Saharan Africa, expressed by the gap in SWAP and TFR, are also visible in other variables such as mortality, life expectancy, GDP per capita or Human Development Indexes. Significant improvements in education in Northern African countries have played an important role explaining these discrepancies, with a decreasing gender gap that has even disappeared in some cases (Courbage, 2014). As a consequence, a demographic revolution started with the widespread use of contraceptives and an increasing age for entering into marriage. Moreover, there were changes in families and their mentalities and increasing women's empowerment. However, the DT has stopped in some countries of North Africa, such as Tunisia, Algeria or Morocco, because of the labour market constraints for women (Courbage, 2014). Women labour participation rates are still quite low in those countries. If women cannot become part of the workforce because they cannot get a respectable job, the risk that these incipient demographic advances might reverse is huge.

Middle, West and East Africa's SWAP is expected to keep rising and to reach Southern Africa's around 2060. The last regions to start their DT are Middle and Western Africa because their TFRs are the last to start declining and their SWAP to begin ascending. While Southern Africa is the region within SubSaharan Africa with the lowest TFR (2.5I in 201020I5), Eastern Africa's TFR is around 5 and Middle and Western still have values between 5 and 6 (characteristic of their incipient DT).

In conclusion, a big demographic gap between North and Sub-Saharan Africa has been generated and is expected to keep increasing in the next decades.

As we have seen, each African country has its own timing for the DT. Some recent researches, such as Wakeman-Linn (20I5), distinguish among three broad groups based on the evolution of their SWAP (Table I).

In Figure 4, we have represented the peak SWAP that each population will attain, their SWAP at the beginning of the DT and the SWAP they had in 2015, based on the World Population Prospects 2015 by United Nations (UN). There are significant differences among countries, with some of them almost reaching their peaks, such as Mauritius, Seychelles, Reunion or Cape Verde, and others barely conserving the initial value, like Niger, or starting their DT, like the DRC. 
Table I: Classification of Sub-Saharan African countries' DT.

The DT is largely complete. Those countries started the DT around the 1960s, at the same time that
East Asia and Latin America, and have almost completed the process. Their transitions were doable
because of rapid reductions in mortality and fertility rates. They experienced some of the greatest
GDP growth in Sub-Saharan Africa during their DT and now they show a middle-income status. This
is the case of Mauritius or Cape Verde.

Little or no transition has yet taken place. They still conserve high rates of fertility and mortality.

Their SWAP will only grow after 2050. This is the case of the Democratic Republic of Congo.

Source: Own elaboration based on Wakeman-Linn (20I5)

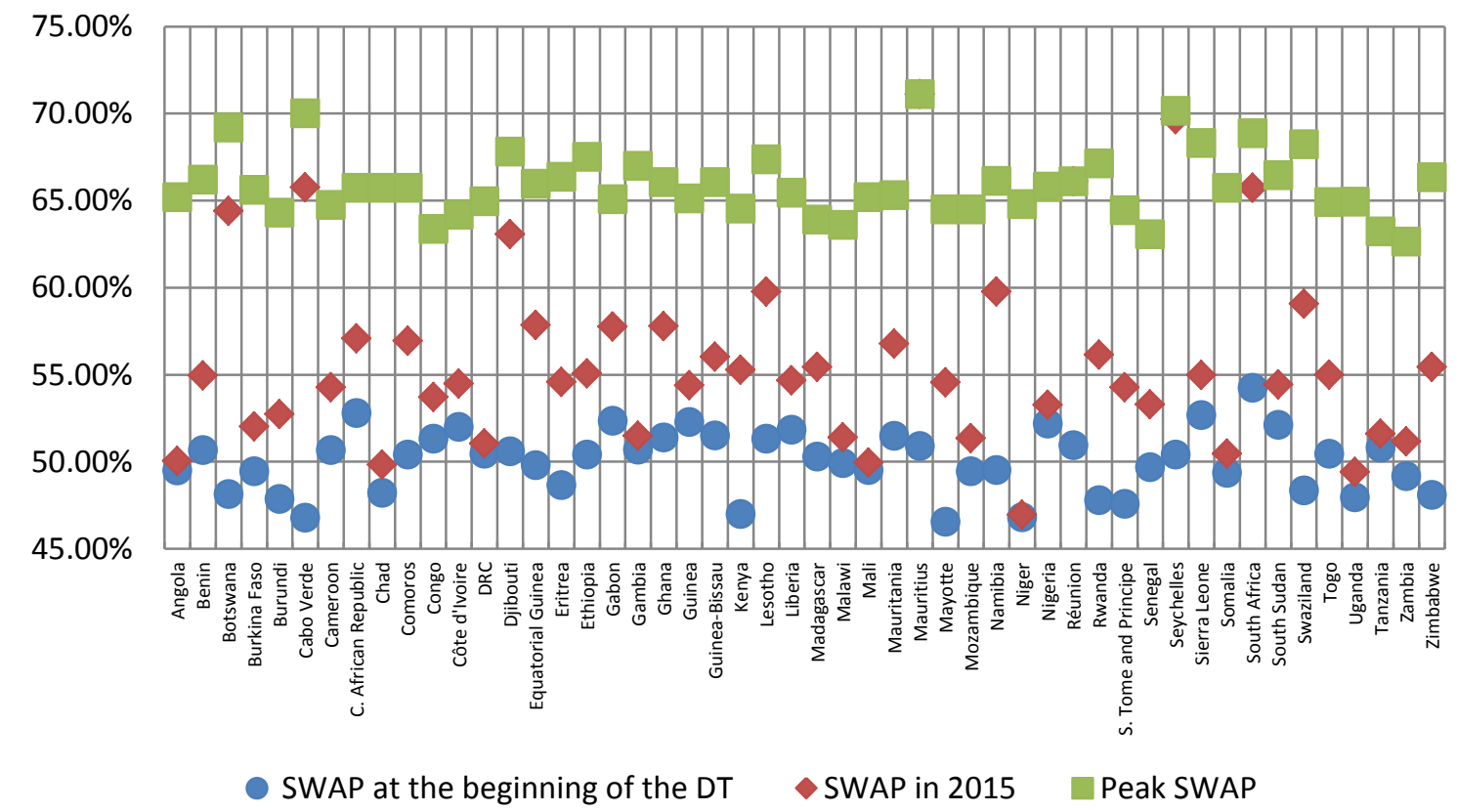

Figure 4: Sub-Saharan Africa: Evolution of the SWAP

Source: Own elaboration with data from UN, World Population Prospects, 2015.

With this data, we have constructed an updated classification of countries. First, we have calculated the mean value for each country between its initial and its peak SWAP. We consider this point as an indicator of half of their DT. Then, we have divided the SWAP in 2015 by the former value representing the $50 \%$ of their DT. As a result, those countries with a value greater than $100 \%$ have already passed
$50 \%$ of their DT (advanced group) and those that have not are part of the incipient group (Figure 5). The highest the percentage, the more advanced the DT is. Hence, the advanced group is formed by the countries between Mauritius and Equatorial Guinea (both included) and the incipient one includes the remaining. 


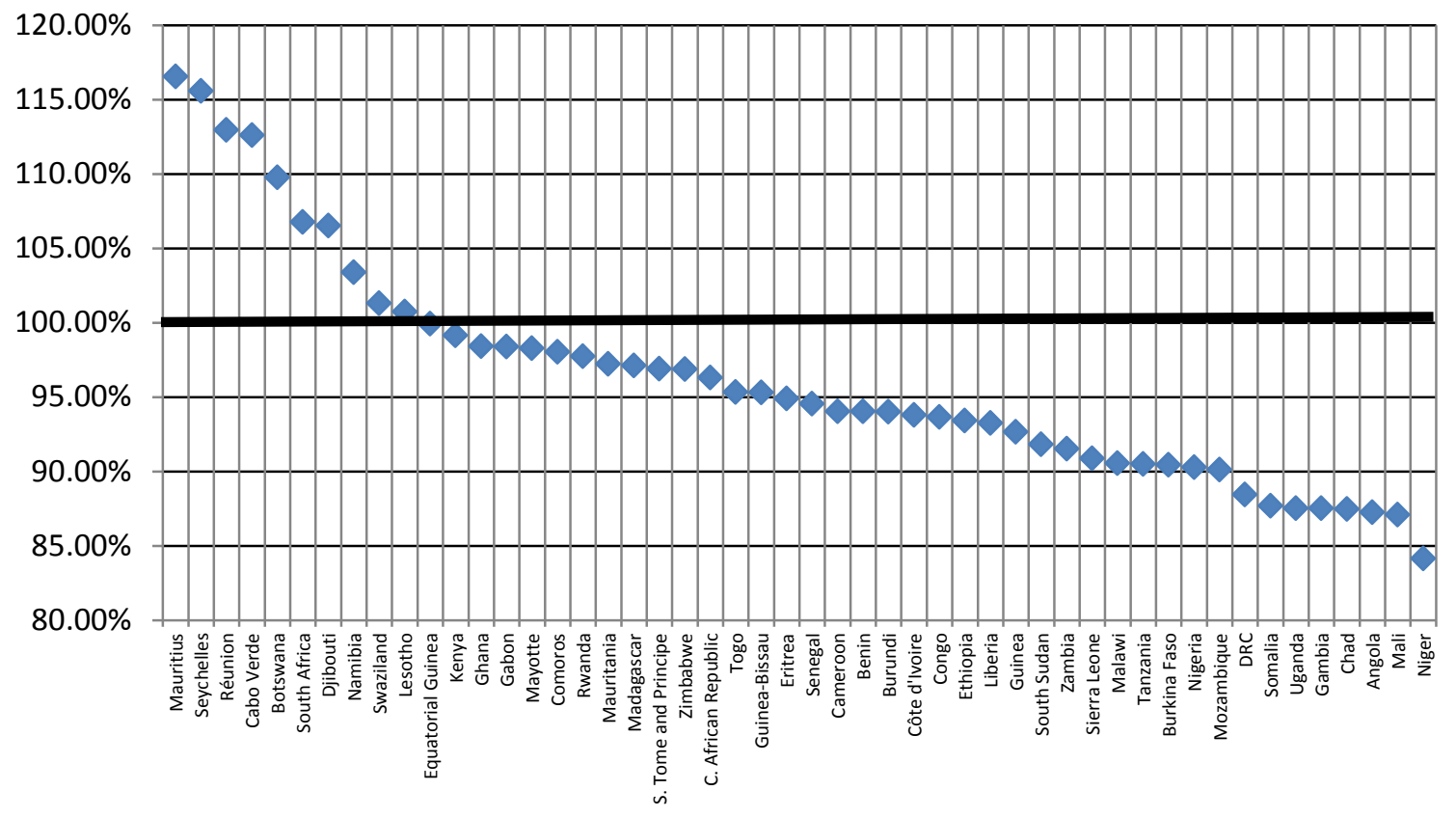

$\checkmark$ SWAP in 2015/ SWAP in the middle of their DT

Figure 5: Sub-Saharan African countries organised by the fulfilment of their DT. Source: Own elaboration with data from UN, World Population Prospects, 2015.

We can conclude, based on this update of Africa's DT, that there are two groups of countries: the advanced group, with countries that have already achieved at least $50 \%$ of their expected DT; and the incipient group, those which have not attained those levels. The DRC is clearly in the latter.

\section{Analysis of DRC}

We have pointed out in the previous section that DRC is recently experiencing its DT. One of the reasons is the slow recovery from the devastating 6year conflict that started in 1996 and caused enormous civilian suffering (Coghlan et al., 2006). DRC's population was 77 million people in 2015, of which $42 \%$ live in urban areas. GNI per capita (\$US) in 2015 was 720, way below Sub-Saharan Africa's average of 3,606 .

First, we analyse its demographic trends and the subsequent population growth. Second, we estimate the prospects for a DD. Finally, we explore DRC's progress towards the achievement of the Millennium Development Goals (MDGs) and identify the remaining challenges. We have chosen the MDGs due to two reasons: first, it has been (jointly with the Sustainable Development Goals (SDGs) the most important international agreed set of goals; and second, because we have found out that improvements in the majority of them could help reap the benefits of $D D$.

In Figure 6, we have depicted DRC's DT. The Crude Death Rate (CDR) has fallen from 25 per
1,000 in 1950 to 10 per 1,000 in 2015 . Furthermore, it is expected to keep declining until the half of this century. This slow decline in mortality is partly explained by the humanitarian crisis lived in this country in the past decades with two wars that started in 1996 and 1998. It is important to remark that only a small proportion of deaths were due to violence, with most attributable to easily preventable and treatable conditions such as malaria, diarrhea, pneumonia and malnutrition (Coghlan et al., 2007). The Crude Birth Rate (CBR) is starting to fall and the SWAP has just taken off. The CBR is projected to keep declining until 2100 , attaining then a value of 15 per 1,000 . The current levels (over 40 per 1,000 ) are over the average of countries of Sub-Saharan Africa. The percentage of married women between 15 and 49 years old who use contraceptive methods is $21 \%$, with only $8 \%$ using modern methods (PRB, 2016). Appendix A shows, in an extended demographic analysis, Total Fertility Rate (TFR), life expectancy at birth, Infant Mortality Rate (IMR) and main causes of death.

The population growth rate in DRC has followed approximately the average path of Africa (Figure 7). It increased (with sporadic mild declines) until the middle of the $90 \mathrm{~s}$, reaching rates greater than $3.5 \%$ in the period 1990-1995. In 1995-2000, an acute drop takes place because of the wars mentioned and the impact of diseases. 


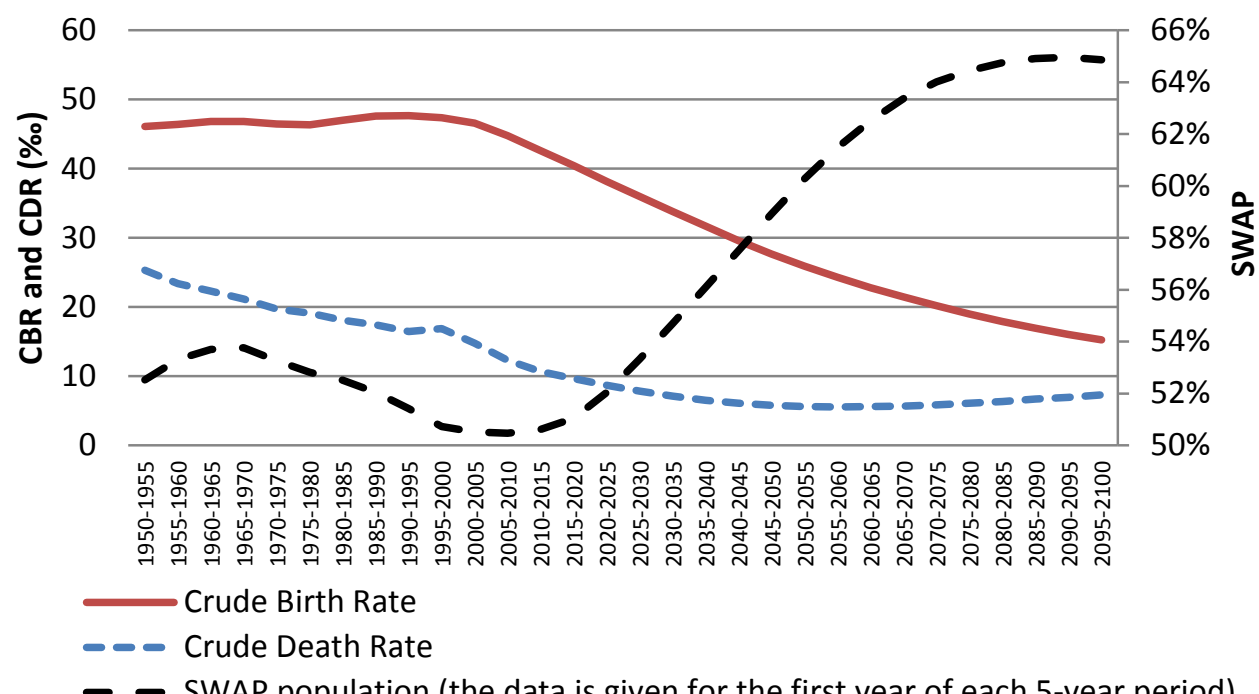

Figure 6: The DT in the DRC (1950-2100)

Source: Own elaboration with data from UN, World Population Prospects, 2015.

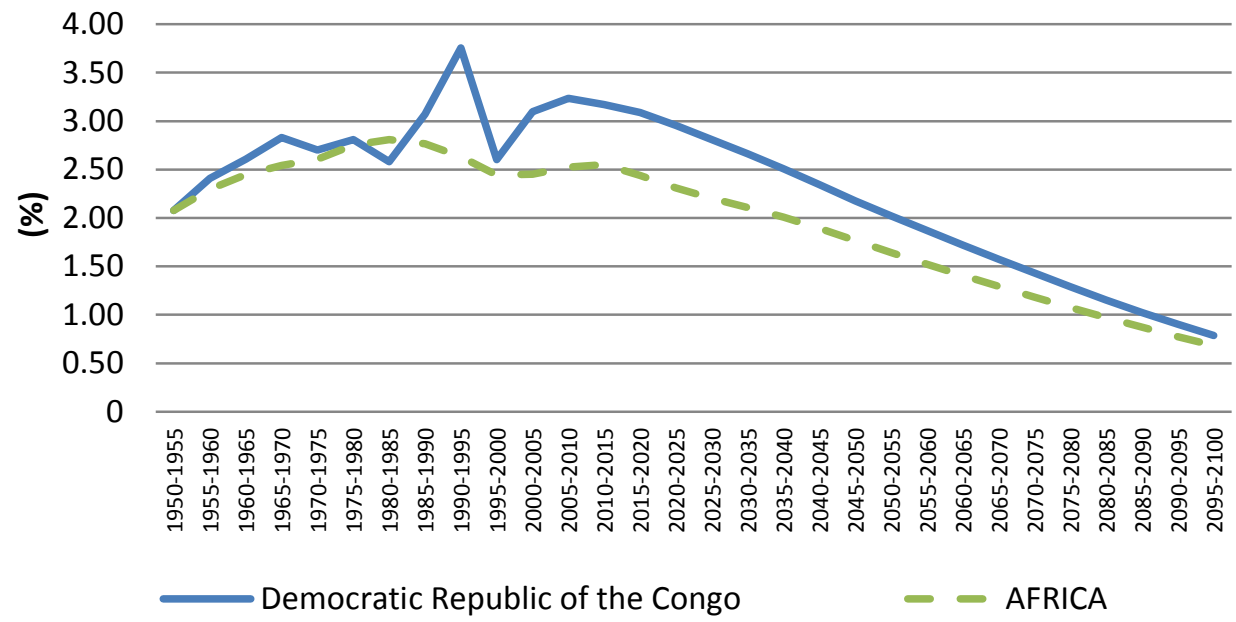

Figure 7: Population Growth Rate (1950-2 100)

Source: Own elaboration with data from UN, World Population Prospects, 2015.

To study the age structure of the population and its evolution we present population pyramids (Figure 8) and some dependency and sex ratios (table 2). The first two pyramids (1950 and 2015) represent expansive populations, with the greatest percentages of population in the youngest ages, high fertility and a reduced life expectancy. However, older age groups are insignificant. Mortality is a serious issue as more than half the people from the generation that was born between 1946 and 1950 were not alive in 2015 (only around 966,000 people were alive out of 2.2 million). 
Democratic Republic of the Congo (1950)

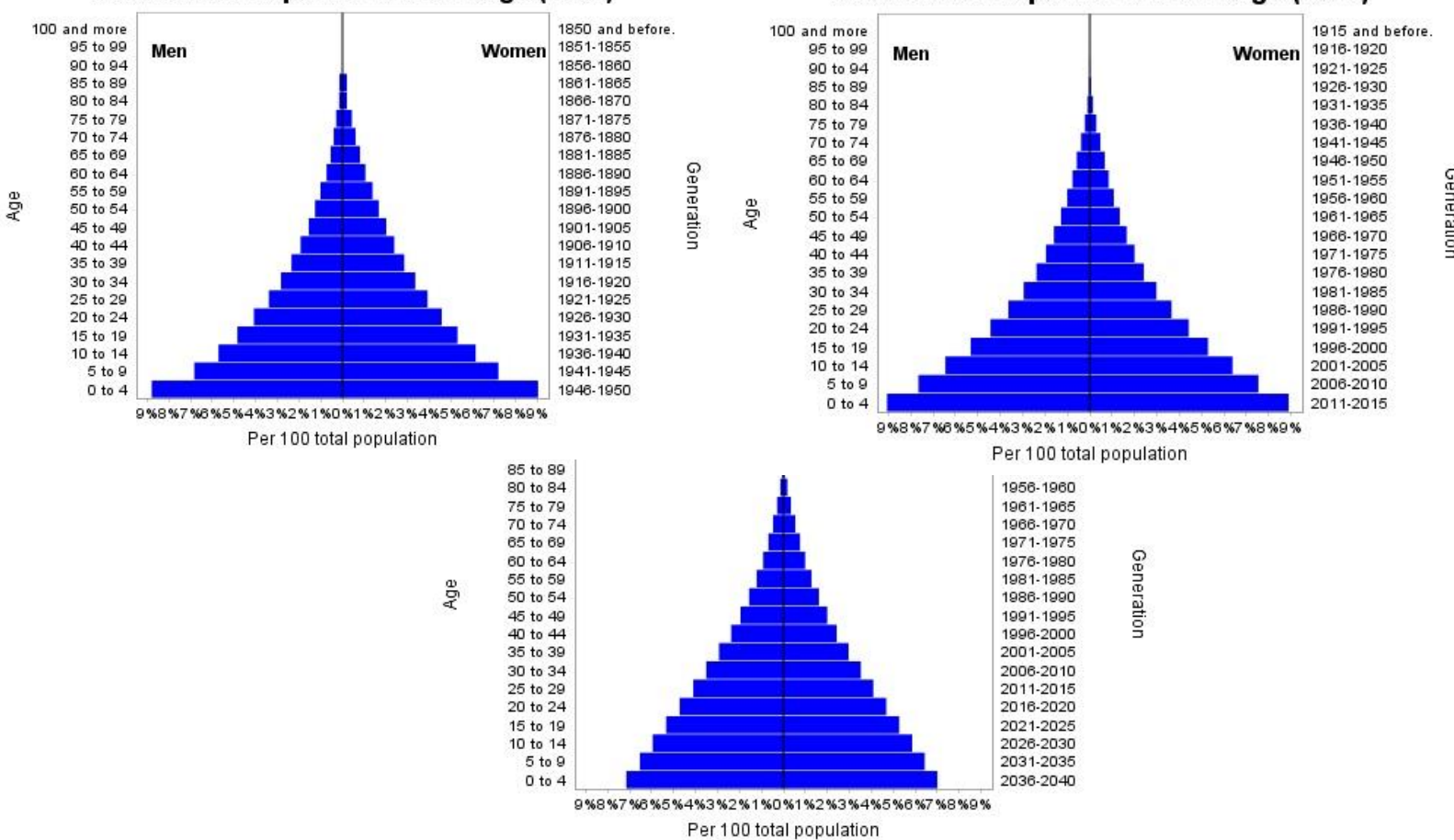

Figure 8: Population pyramids of the DRC (1950, 2015, and 2040).

Source: Own elaboration with data from UN World Population Prospects (2015).

In the estimation for 2040, we clearly see the effects of the incipient DT. Births are fewer (fertility has declined) so there is a smaller proportion of young cohorts. Furthermore, we observe improvements in life expectancy as represented by greater percentages of people reaching 65 and above. Out of those 2.2 million born between 1946 and 1950,
50,000 people are estimated to make it to $90-94$ years old in 2040, with women almost doubling men. Nevertheless, it is still an expansive population in which the young population has a remarkable weight in relation to other age groups.

Table 2: Dependency and sex ratios for DRC (\%)

\begin{tabular}{cccc}
\hline & 1950 & 2015 & 2040 \\
\hline Total dependency ratio & 90.39 & 95.92 & 73.92 \\
\hline Children dependency ratio & 83.18 & 90.11 & 67.74 \\
\hline Old-age dependency ratio & 7.21 & 5.81 & 6.17 \\
\hline Proportion of women (0-14) & 51.16 & 49.60 & 49.56 \\
\hline Proportion of women (15-64) & 54.35 & 50.31 & 50.14 \\
\hline Proportion of women (65+) & 59.87 & 55.30 & 53.53 \\
\hline Total proportion of women & 53.16 & 50.13 & 50.04 \\
\hline
\end{tabular}

Source: Own elaboration with data from UN, World Population Prospects, 2015.

High child and total dependency ratios also prove the incipient DT. They are both expected to fall decidedly with the fertility fall by 2040 . On the other hand, the old-age dependency ratio is predicted to increase because of greater longevity and people attaining higher ages. Although for Kabeya and Nyindo (2016) the situation around 2010 was so incipient that it was more accurate to say that the country was at the entrance of the DT, long term estimations prove the transition is certain.

In this section, we make use of the methods explained in section 3 to break down the GDP per capita, showing the SWAP as one of its components, 
and then we calculate the annual growth rate of each component to show their contribution.

In table 3 we first measure GDP per capita components in 1960, 1980 and 2014. The first column shows that in 1960 GDP per capita was 2,270 USD (at 20I I prices), and reduced to I,698 in 1980 and even further to 787 in 2014. These statistics depict a dire economic (and humanitarian) situation. The second column measures labour productivity, which also decreased dramatically. The third column is the employment rate (over the working-age population) which decreased but not so dramatically. The last column is the SWAP (share of the workingage population) which decreased only slightly over those years. In summary, GDP falls because productivity falls. In the table, we also show the forecasted values of SWAP estimated by United Nations for 2040 and 2100, showing important increases.

In the second panel of table 3, we have computed the annual growth rates of the components of per capita GDP. For the period 1960-1980 GDP per capita has fallen at an annual rate of $1,37 \%$ due to a fall in productivity of $1,03 \%$ and due to a decrease in the employment rate of $0,24 \%$ with a small contribution to this fall by a declining SWAP. For the period 1980-2014, the DRC's GDP per capita continued to fall at an annual rate of $2.33 \%$ due to a fall of $2.18 \%$ of its productivity per worker, with almost constant employment rate and SWAP.

Table 3: Breakdown of GDP per capita in DRC.

\begin{tabular}{|c|c|c|c|c|}
\hline & $Y / N(a)$ & $\mathrm{Y} / \mathrm{L}(\mathrm{a})$ & L/N16-64 (\%) & N16-64/N (\%) \\
\hline 1960 & 2,270 & 6,392 & 66.14 & 53.70 \\
\hline 1980 & 1,698 & 5,147 & 62.84 & 52.51 \\
\hline 2014 & 787 & 2,430 & 61.49 & 51.04 \\
\hline 2040 & & & & 57.50 \\
\hline 2100 & & & & 64.64 \\
\hline \multicolumn{5}{|c|}{ Annual Growth Rates } \\
\hline & $\mathrm{Y} / \mathrm{N}$ & $\mathrm{Y} / \mathrm{L}$ & L/N16-64 & N16-64/N \\
\hline $1960-1980$ & $-1.37 \%$ & $-1.03 \%$ & $-0.24 \%$ & $-0.11 \%$ \\
\hline $1980-2014$ & $-2.24 \%$ & $-2.18 \%$ & $-0.06 \%$ & $-0.08 \%$ \\
\hline 2015-2040 & & & & $0.48 \%$ \\
\hline $2040-2100$ & & & & $0.20 \%$ \\
\hline
\end{tabular}

Notes: (a) USD constant prices

Source: Own elaboration with data from the Penn World Table 9.0 and UN World Population Prospects, 2015.

The most important result is that in the next decades the SWAP (NI6-64/N) is estimated to grow at an annual rate of $0.48 \%$ for the period $2015-40$ and at a rate of $0.20 \%$ for the period $2040-2100$, thus affecting positively GDP per capita growth for both periods.

More detailed results are shown in Figure 9, where data for each five-year period is presented. SWAP began to increase slightly in 2010 , producing a first small DD of $0.06 \%$ (that is the annual increase in GDP per capita generated). The following increases of SWAP will be more and stronger up to 2035, with a maximum DD of $0.51 \%$. After 2035, SWAP will continue increasing but at lower rates up to a maximum SWAP of $64.96 \%$ in 2090 , and afterwards will start to decrease, producing a negative $D D$ after that year. 


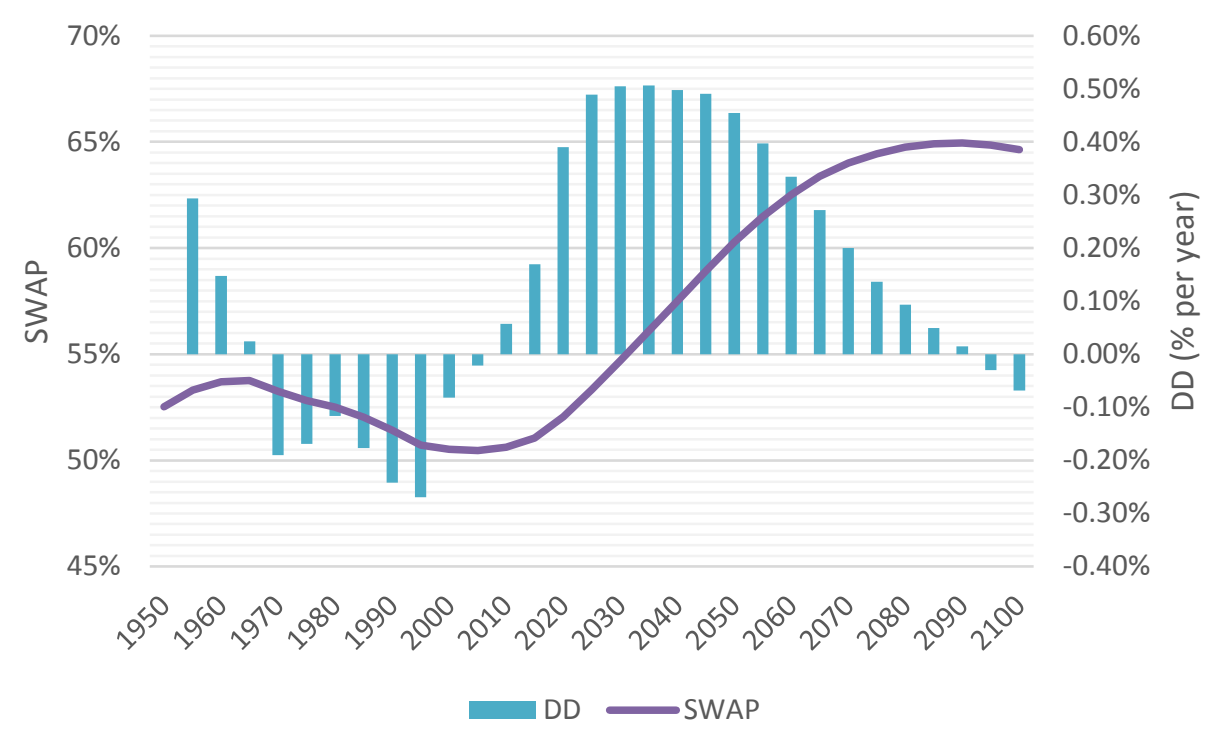

Figure 9. SWAP and Demographic Dividend (DD) in DRC

Source: Own elaboration with UN World Population Prospects, 2015.

This is the expected DD. We believe it can happen under the circumstances explored in the next section.

\section{Discussion: policies to secure a real change}

As we have already seen, the DRC's population is characterized by its youthfulness. With the expected increases in the SWAP, a significant percentage of the population will enter the working-age and the DRC needs to create opportunities to generate new jobs to satisfy this increasing labour supply, especially in the formal sector, to maintain the employment rate. The expected DD could contribute to economic growth according to the policies undertaken.

In this section, we explore some of the main areas where changes are needed, and the country's intervention could generate more benefits. To base this analysis, we will focus on the progress made towards the achievement of the Millennium Development Goals (MDG) and some other socioeconomic indicators. Then, we will derive the subsequent challenges.

There are several possible methods to evaluate the MDGs. For this study, we use the method of notation adopted by the CAS in 2012. Therefore, to assess the performance achieved by each indicator, a score between 0 and $I$ is assigned. It materializes the degree of achievement of objectives previously set by the DRC. The method measures the difference, in terms of ratios, between the value reached and the value one should attain. It is important to take into account the objective pursued in the calculation of the score to be assigned to each indicator. If the objective is to decrease the basic value of the indicator, the scoring formula is as follows:

$$
\text { Score }=\frac{\text { Target value }}{\text { Value obtained }}
$$

If, on the other hand, the objective is to increase the basic value of the indicator, the preceding formula becomes:

$$
\text { Score }=\frac{\text { Value obtained }}{\text { Target value }}
$$

By averaging the scores of the indicators, it is possible to assess the score by objective. A global score is then assigned to the country by making an arithmetic average of the scores obtained at the level of the 7 MDGs selected.

Table 4 shows that many targets and indicators have not achieved the target value set in 2015. Out of the 21 indicators used in this study, only three indicators were achieved at more than $85 \%$ and at the target level. Out of the 7 MDGs analysed, only in the last two MDGs $85 \%$ of them was reached. Globally and taking account of the 21 indicators analysed, the score achieved by the DRC is 0.79 . If we could create three ranking groups according to the performance achieved, as the best-performing countries have a score greater than or equal to 0.9 ; the performers have a score varying between 0.8 and 0.9 and the worst performing ones less than 0.8 ; the DRC would be ranked in the lowest performers. Those results lead us to the following observations:

I) In order to eradicate extreme poverty and hunger in the DRC, policies and strategies or simply government measures have been developed and implemented to stimulate job creation. Among other policies, Lututala (2017) underlines the pacification of 
the country, the improvement of the business environment, the construction and rehabilitation of basic infrastructures, the supply of electricity, school training, health services, youth employment programs, etc. As an indicator, the author shows that the share of public expenditure in the education sector in the national budget has increased from 6\% in $2005-2007$ to $13,8 \%$ in 2013 ; and that of health from $23.9 \%$ to $53.1 \%$ during the same period.

However, despite these efforts, poverty continues to be a mass phenomenon as $63.4 \%$ of the Congolese population continue to live below the poverty line (estimated at \$ I.25) and the unemployment rate remains very high $(24.7 \%$ for young people in urban areas) in the country. Certainly, during the underlying period, the DRC has achieved remarkable growth $(6.3 \%$ in 2002 and a peak of $9.5 \%$ in 2014) which has exceeded even the African average. However, Congolese economic growth has not been inclusive and the mining sector has been the main gear of growth while it creates little-added value and jobs, and is often affected by the backlashes of global markets. In addition, the policies and strategies implemented by the Congolese government do not meet the needs of its population. In such circumstances, malnutrition and inadequate food consumption increase (for example, $69.1 \%$ of children under 5 are underweight) and household purchasing power decreases. Lututala (2017) adds that $1 / 3$ of Congolese children frequently suffer from malaria and $17 \%$ from diarrhea. This may be one of the causes of the high infant mortality rate in the DRC $(58$ per I,000) as well as that of children under 5 ( 104 per I,000). The fact that very few people have access to drinking water (50.4\%), a better sanitation system $(56.1 \%)$ and sanitary toilets $(20.5 \%)$ in the DRC can be among other main factors of these recorded mortalities.

The results also show that many women die in childbirth, causing a maternal mortality rate (846 per 100,000 ) among the highest in Africa. This is explained by the fact that $20 \%$ of women give birth without being assisted by qualified health personnel in the country.

Table 4. Assessment of the progress made by the DRC in achieving the MDGs.

\begin{tabular}{|c|c|c|c|}
\hline Indicators by objective & End of year 2013 & 2015 target & Score obtained \\
\hline \multicolumn{4}{|l|}{ MDG 1: Eradicate extreme poverty and hunger } \\
\hline Incidence of poverty & $63.40 \%$ & $40 \%$ & 0.63 \\
\hline Unemployment rate of urban youth aged 15 to 24 & $24.70 \%$ & $10 \%$ & $\mathbf{0 . 4 0}$ \\
\hline Proportion of children under 5 years who are underweight & $22.60 \%$ & $14 \%$ & 0.62 \\
\hline AVERAGE SCORE MDG 1 & & & 0.55 \\
\hline \multicolumn{4}{|l|}{ MDG 2: Ensure primary education for all } \\
\hline Net primary school enrolment rate & $80.40 \%$ & $100 \%$ & $\mathbf{0 . 8 0}$ \\
\hline $\begin{array}{l}\text { Proportion of pupils starting grade } 1 \text { in primary education and } \\
\text { completing grade } 5\end{array}$ & $69.10 \%$ & $100 \%$ & 0.69 \\
\hline Literacy rate for people aged from 15-24 year & $82.40 \%$ & $100 \%$ & $\mathbf{0 . 8 2}$ \\
\hline AVERAGE SCORE MDG 2 & & & $\mathbf{0 . 7 7}$ \\
\hline \multicolumn{4}{|l|}{ MDG 3: Promote gender equality and empower women } \\
\hline Percentage of women employed in the non-agricultural sector & $18.60 \%$ & $30 \%$ & 0.62 \\
\hline Proportion of seats occupied by women in parliament & $9.80 \%$ & $30 \%$ & $\mathbf{0 . 3 3}$ \\
\hline Literacy rate of women aged 15-24 compared to men & 0.736 & 1.00 & $\mathbf{0 . 7 4}$ \\
\hline Girls/boys ratio in primary education & 0.97 & 1.00 & 0.97 \\
\hline Girls/boys ratio in secondary education & 0.75 & 1.00 & $\mathbf{0 . 7 5}$ \\
\hline Girls/boys ratio in higher education & 0.5 & 1.00 & $\mathbf{0 . 5 0}$ \\
\hline AVERAGE SCORE MDG 3 & & & 0.65 \\
\hline \multicolumn{4}{|l|}{ MDG 4: Reduce the mortality of children under 5} \\
\hline Mortality rate of children under 5 (per 1,000$)$ & 104 & 60 & $\mathbf{0 . 5 8}$ \\
\hline Infant mortality rate (per 1,000$)$ & 58 & 30 & 0.52 \\
\hline AVERAGE SCORE OMD 4 & & & 0.55 \\
\hline \multicolumn{4}{|l|}{ MDG 5: Improve maternal health } \\
\hline Maternal mortality rate (per 100,000$)$ & 846 & 322 & $\mathbf{0 . 3 8}$ \\
\hline $\begin{array}{l}\text { Proportion of deliveries (birth cases) assisted by qualified health } \\
\text { personnel }\end{array}$ & $80.10 \%$ & $100 \%$ & 0.80 \\
\hline AVERAGE SCORE OMD 5 & & & 0.59 \\
\hline \multicolumn{4}{|l|}{ MDG6: Combat HIV / AIDS, malaria and other diseases } \\
\hline HIV prevalence rate & $1.20 \%$ & $3.10 \%$ & 2.58 \\
\hline Rates of condom use among women aged 15-49 & $12.20 \%$ & $100 \%$ & $\mathbf{0 . 1 2}$ \\
\hline Proportion of children under 5 who sleep under treated mosquito nets & $55.90 \%$ & $100 \%$ & 0.56 \\
\hline SCORE AVERAGE MDG 6 & & & 1.57 \\
\hline \multicolumn{4}{|l|}{ MDG 7: Ensure a sustainable environment } \\
\hline /aps.journals.ac.za & & & 4286 \\
\hline
\end{tabular}


$\begin{array}{llll}\text { Proportion of the urban and rural population with sustainable access } & 50.40 \% & 71 \% & \mathbf{0 . 7 1}\end{array}$ to an improved water source

\begin{tabular}{llll}
\hline Proportion of urban population with access to improved sanitation & $56.10 \%$ & $55 \%$ & $\mathbf{1 . 0 2}$ \\
\hline Population of the population using hygienic toilets & $20.50 \%$ & $\mathbf{0 . 8 2}$ & \\
\hline AVERAGE SCORE MDG 7 & & $\mathbf{0 . 8 5}$ & \\
\hline GLOBAL SCORE & & $\mathbf{0 . 7 9}$ & \\
\hline
\end{tabular}

Source: Own elaboration with data from A. Izu and B. Mulolo (2017) and the Ministry of Planning (2015)

In order to eradicate extreme poverty and hunger effectively in the DRC and improve the health conditions of the population, adequate, combined and well-coordinated policies are needed. Not only will it be necessary to invest in pro-poor sectors (agricultural value chains, finance and rural infrastructure), professional training for inclusive and pro-poor growth, but also in combined and effective population policies for an effective transition leading to the demographic dividend. Admittedly, in a context of globalization, although not yet evaluated, agricultural value chain development, private sector development and vocational training programs are being promoted in DRC by bilateral partners such as USAID, DFID and the Swiss Cooperation for Development with a view to eliminate poverty and promote sustainable and inclusive socio-economic development. But a development policy that will forget or annihilate the role of the demographic variable in the process of economic growth and development of the DRC is unlikely to achieve results in the long term. The research of several authors like Guengant, Mangulu and Mavula (2014) and Lututala (2017) reached the same findings. Employment has to grow at an unprecedented rate and it should shift towards high productivity sectors. This requires a stable macroeconomic environment in which governments play an essential role. It is essential to assist rural areas and guarantee access to financial services. In addition, it is important to promote formal entrepreneurship, to develop local and national strategies, to develop business and to enhance inclusive economic growth.

2) The Congolese government and its partners have certainly made efforts to improve the access to and quality of education in general and more precisely primary education in the country. These efforts translate into an increase in the share of the education sector in the national budget. In addition, the Congolese legislator, through Act 43 of the Congolese constitution, enshrines the free and compulsory nature of primary education.

However, impoverished by decades of conflict, violence, and instability, DRC has failed to reach the UN goal of "Education for All" (2000-2015). The following data show that many education needs are not yet met in the DRC. Though education remains the best gear of development, we find that in 2013; $20 \%$ of children of primary school age still do not go to school and; more than $17 \%$ of people aged 15 to 4287
24 are illiterate and more than $30 \%$ of children who start primary school do not complete grade 5; they are forced to give up. Not only are these rates higher in rural areas and that girls remain the first victims compared to boys, but also the quality of education received in the DRC remains low compared to other African countries (PASEC, 2014). Girls are at the highest risk to drop out (40\%), and girls of rural and uneducated parents are at the highest risk to never go to school (33\%) (DRC's National Education System, 2017). In a context of demographic survival strategies in families, questioning the value of education following unemployment and the failure or weakness of the state to provide public services such as education and health to all its population, combined and well-coordinated policies are needed to improve universal access to quality education but also the employability of trained people in the DRC.

3) In April 20II, a bill on gender parity was approved by the Parliament and in 2015, the revision of the electoral law dropped the $30 \%$ quota for women, which is considered a retrogressive sign. However, gender relations are determined by strong male-dominant gender norms. Besides, the DRC Family Code still discriminates against women, limiting their economic and social opportunities (African Development Bank, 20I3). Women's labour force is concentrated in agriculture and the informal sector. Even if women represent more than $52 \%$ of the Congolese population, their political participation is limited in the country: In the national government and National Assembly; women account respectively for only 10\% (6 women about 59 ministers) and $9,8 \%$. Additionally, in its 57 years of independence, the DRC has never had a woman prime minister. Moreover, women's rights are often not protected and early marriage of girls is prevalent (the mean age of the first birth is estimated at 20). Early marriage results in the low education levels of women resulting from school dropouts, imbalanced power relations at home, and reproductive health problems.

Thus, policies promoting the socio-economic empowerment of women should be promoted and the gender approach should be a cross-cutting theme for any development program in DRC. Women should also work and be encouraged to participate and be empowered in decision-making positions. Family planning should also be encouraged to allow women to have time for personal growth but also to take on decision-making responsibilities.

http://aps.journals.ac.za 
Finally, the development policies and strategies implemented by DRC and its partners have not been effective in achieving the targets set in the context of the MDGs. Not only the context in which they were implemented was difficult and characterized by political instability but also these policies and strategies did not sufficiently integrate the demographic phenomena as an endogenous variable.

With the Sustainable Development Goals (approved in 2015), higher quality education, climate change, multiple inequalities, innovation, sustainable consumption, peace and justice, are the new priorities. In the DRC, the success of these goals will depend on the institutional framework, the civic structures and the manner the policies and strategies have been defined and implemented. Without sufficient focus on human capital, inclusive and participative governance and democracy and human rights promotion, it will be unrealistic to promote sustainable development in DRC.

\section{Conclusion}

The potential of Sub-Saharan Africa to enjoy a DD is exceptional. In the following years, the TFR is predicted to descend and the SWAP to increase, representing a window of opportunity for a DD to occur. This first DD is transitory and it lasts as long as the working age population is increasing faster than the total population and the dependency ratio falls. Eventually, the SWAP will begin to decline as the cohorts retire and, with low mortality and greater life expectancy, the dependency ratio will rise again. This ageing population situation can lead to a permanent second DD due to the fact that the population has more incentives to save and the elderly share is incrementing.

Cross-regression models have proved the relationship between a declining fertility rate (and an increasing SWAP) and GDP per capita. Besides, macrosimulation models have helped to underline the numerous channels by which the reduction of fertility affects economic growth. The most important conclusion is that this positive effect is not automatic; hence, it depends on the policies which must come to terms with the situation of its region. Sub-Saharan African countries have to eliminate the obstacle of a huge fertility by promoting contraceptives use, sexual education and family planning programs. These actions have proved to efficient in reducing fertility rates. Moreover, they need to empower women and encourage their access not just to the labour market but to respectable jobs. Furthermore, actions towards making health care and education accessible and skills development of the youth (professional training based on market needs) are fundamental.
Sub-Saharan Africa shows a clear delay when comparing to other regions or continents. Until now, the DT has been a longer and slower process. In addition, the gap between Northern and Sub-Saharan Africa is widening, with the North approximating to develop countries and Sub-Saharan Africa remaining a long way behind. Within Sub-Saharan African regions, we have found that Western and Central Africa are the most underdeveloped.

We classify the DRC in the group of the least advanced, where the first dividend has not contributed yet to the DRC growth as its DT is just beginning. Its TFR is still elevated but has commenced to slowly fall during this century. The use of contraceptives is almost non-existent. Besides, the sex and age structure of its population is pyramidal shaped with children and total dependency ratios expected to increment. Life expectancy at birth remains low and the fall in mortality rates has been slow due to the political and social situation of the country. Wars initiated during the last decade of the past century led to a humanitarian crisis that heavily impacted the country. It is worth emphasizing that the greatest cause of death has not been violence but diseases outbreaks.

Although the DRC is still one of the poorest countries in the world, this could change in the upcoming years if the country manages to make the most of its demographic situation, as our estimations have predicted. The main component of the first DD is an increasing SWAP, which is key to GDP per capita's growth. To promote it, the country has to start encouraging fertility rates' fall. But many other policies have to be implemented to secure a real change.

Focusing on the advancements made towards the achievement of the MDGs, we have identified urgent needs and targeted strategies to eradicate extreme poverty and hunger, to improve health conditions of the population, to enhance inclusive economic growth, to improve the access to and the quality of education and to promote the socio-economic empowerment of women.

The DRC has experienced recent dramatic conflicts and adverse conditions. The country is still recovering; thus, advancements are fragile and slow. However, acknowledging all these circumstances, the future is largely in the hands of governments and their responses to current challenges. The elections on December 2018 could become the first step to a more democratic and transparent society with a chance to operate better than previous governments. Although international institutions and external humanitarian aid can largely contribute to real changes, we believe that a strong and reliable national leadership is absolutely required. 


\section{Author/s Guarantee Form}

We the authors of the paper claim to have contributed sufficiently to the work presented and that the content of the manuscript has never been previously published.

\section{References}

African Development Bank (20/3) Democratic Republic of Congo 2013-2017 country strategy paper. Regional Department Centre. Retrieved from:

https://www.afdb.org/fileadmin/uploads/afdb/Doc uments/Project-and-

Operations/Democratic\%20Republic\%20of\%20 Congo\%20-\%202013-2017\%20-

\%20Country\%20Strategy\%20Paper.pdf

Ashraf, Q.H., Weil, D.N. and Wilde, J. (2013) The effect of fertility on economic growth. Population and Development Review, 39 (I), pp. 97-130.

Bloom, D.E. (2016) Convulsión demográfica. Finanzas \& Desarrollo, Marzo, pp. 0-5.

Bloom, D.E., Canning, D., Fink, G. and Finlay, J.E. (2009) Fertility, female labor force participation, and the demographic dividend. Journal of Economic Growth, I4 (2), pp. 79-101.

Bloom, D.E., Kuhn, M. and Prettner, K. (2016) Africa's Prospects for Enjoying a Demographic Dividend. NBER Working Paper Series, 22560. Cambridge: National Bureau of Economic Research.

Canning, D., Raja, S. and Yazbeck, A. (2015) Africa's Demographic Transition; Dividend or Disaster?. Washington DC: World Bank Group. Retrieved from

https://openknowledge.worldbank.org/handle//09 86/22036

Coghlan, B., Brennan, R.J., Ngoy, P., Dofara, D., Otto, B., Clements, M. and Stewart, T. (2006) Mortality in the Democratic Republic of Congo: a Nationwide Survey. Lancet, 367 (9504), pp. 4451.

Coghlan, B., Ngoy, P., Mulumba, F., Hardy, C., Bemo, V.N., Stewart, T., Lewis, J., and Brennan, R. (2007) Mortality in the Democratic Republic of Congo: An Ongoing Crisis. International Rescue Committee. Retrieved from http://www.rescue.org/sites/default/files/migrated/ resources/2007/2006-7_congomortalitysurvey.pdf

Courbage, Y. (20I4) iHa cumplido sus promesas la transición demográfica en el sur del Mediterráneo? Quaderns de La Mediterrània, 20 21 , pp. |75-|8|.

Dabire, J-M. V., Bamou, E. and Mutumbi Kalongania, J.A. (2017) République Démocratique du Congo 2017. Perspectives Economiques en Afrique. African Economic Outlook. Retrieved from: http://www.africaneconomicoutlook.org/fr/notespays/republique-democratique-du-congo

Drummond, P., Thakoor, V. and Yu, S. (20I4) Africa rising: harnessing the demographic dividend. IMF Working Paper No. I4/I43. International Monetary Fund. Retrieved from: https://doi.org/I0.5089/978 I498379878.00 I.

Galor, O., and Weil, D.N. (2000) Population, technology, and growth: from malthusian stagnation to the demographic transition and beyond. The American Economic Review, 90 (4).

Guengant J-P., Mobhe Agbada, M. and Mavula Banda, N. (2014) Bénéficier du dividende démographique? Replacer la population au centre des trajectoires de développement de la République Démocratique du Congo. Kinshasa; Paris: PARSS; AFD. Retrieved from: http://www.documentation.ird.fr/hor/fdi:0100680 24

International Fund for Agricultural Development (20/3) Rural poverty in the Democratic Republic of the Congo. Retrieved from: https://operations.ifad.org/web/rural-povertyportal/country/home/tags/dr_congo\#maincontent

Izu, A. and Mulolo, B. (20|7), Evaluation of the Millennium Development Goals in DRC: which lessons for the Sustainable Development Goals?, Université de Kinshansa, MPRA Paper No. 80493.

Kabeya M., Simon I. and Nyido Mpyana, J. (2016) Niveau de transition démographique de la République Démocratique du Congo. International Journal of Innovation and Applied Studies, I8 (4), pp. I I77-I I 96.

Kandala, N-B., Mandungu, T.P., Mbela, K., Nzita, K.P.D., Kalambayi, B.B., Kayembe, K.P. and Emina, J.B.O. (2014) Child mortality in the Democratic Republic of Congo: cross-sectional evidence of the effect of geographic location and prolonged conflict from a national household survey. BMC Public Health, I4, pp. I-9.

Karra, M., Canning, D. and Wilde, J. (2015) A simulation model of the effect of fertility on economic growth in Africa. Working Paper 315. University of South Florida, Department of Economics.

Lee, R. and Mason, A. (2006) ¿Cuál es el dividendo demográfico?. Finanzas \& Desarrollo, Septiembre, pp. 16-17.

Lututala, B.M. (2017) L'économie congolaise à l'épreuve de la dynamique démographique. Cahiers Économiques et Sociaux, Numéro spécial.

Mabika, C. and Shapiro, D. (20I2) School enrollment in the Democratic Republic of Congo: family economic well-being, gender and place of 
residence. African Population Studies, Vol. 26, 2, pp. 197-220.

Martín Ruiz, J.F. (2007) La pauta poblacional de África: los desiguales niveles de la transición demográfica. Estudios Geográficos, 68, 262, pp. |39-|7|.

Mason, A. (2005) Demographic transition and demographic dividends in developed and developing countries. United Nations Expert Group Meeting on Social and Economic implications of Changing Population Age Structure, Mexico. Retrieved from: https://doi.org/I0.1017/CBO978II074I5324.004

Mason, A., Lee, R. and Jiang, J.X. (2016) Demographic dividends, human capital, and saving. Journal of the Economics of Ageing, 7, pp. 106-122.

Mason, A., Lee, R., Abrigo, M. and Lee, S-H (2017) Support ratios and demographic dividends: Estimates for the World, UN Population Division. Retreived from: http://www.un.org/en/development/desa/populati on/publications/pdf/technical/TP20 I 7-I.pdf

UNDP (2015) Rapport OMD 2000-20I5 - UNDP: Evaluation des progrès accomplis par la République Démocratique du Congo dans la réalisation des Objectifs du Millénaire pour le développement. Retrieved from: http://cd.one.un.org/content/unct/rdc/fr/home/pu blications/rapport-omd-2000-20 I5.html

UNFPA (20l4) Los adolescentes, los jóvenes y la transformación del futuro. UNFPA, pp. |3-3|. Retrieved from: https://www.unfpa.org/sites/default/files/pubpdf/SWOP2014 Report Web Spanish.pdf

UNICEF (2015) Committing to Child Survival: A Promise Renewed - Progress Report 2015. New York: UNICEF. Retrieved from: http://www.unicef.org.mz/wpcontent/uploads/2015/09/A-Promised-Renewed20I5.pdf
PASEC (2015) Education system performance in francophone sub-Saharan Africa: Competencies and learning factors in primary education. Dakar: PASEC; Confemen. Retrieved from: http://www.pasec.confemen.org/wpcontent/uploads/2015/I2/Rapport_Pasec20I4_GB webv2.pdf

Teller, C.H., Hailemariam, A., Gebreselassie, T. and Seifu, Y. (20II) The uniqueness of the Ethiopian demographic transition within sub-Saharan Africa: multiple responses to population pressure, and preconditions for rural fertility decline and capturing the demographic dividend. African Population Studies, 25 (2).

Thakoor, V., and Wakeman-Linn, J. (2016) Subirse a la ola demográfica. Finanzas \& Desarrollo. Marzo, pp. 22-25.

United Nations, Department of Economic and Social Affairs, Population Division (20/5). World Population Prospects: The 2015 Revision, Key Findings and Advance Tables. Working Paper No. ESA/P/WP.24I.

Wakeman-Linn, J. (20I5) How can Sub-Saharan Africa harness the demographic dividend? IMF Regional Economic Outlook, pp. 25-45.

World Bank (2010) Le système éducatif congolais. Diagnostic pour une revitalisation dans un contexte macroéconomique plus favorable. Washington, DC: World Bank. Retrieved from: http://documents.worldbank.org/curated/en/8I56 7|468262531676/Congo-Le-systeme-educatifcongolais-diagnostic-pour-une-revitalisation-dansun-contexte-macroeconomique-plus-favorable

World Health Organisation (2014) The health of the people. What works. The African Regional Health Report. WHO Regional Office for Africa. Retrieved from: http://extranet.who.int/iris/restricted/bitstream/10 $665 /|37377 / 4 / 97892902326| 2 . p d f$ ua $=$ I 